\title{
Sarcoptes scabiei: Specific immune response to sarcoptic mange in the Iberian ibex Capra pyrenaica depends on previous exposure and sex
}

\author{
Mathieu Sarasa ${ }^{\mathrm{a}, \mathrm{b}, *}$, Luisa Rambozzi ${ }^{\mathrm{c}}$, Luca Rossi ${ }^{\mathrm{c}}$, Pier G. Meneguz ${ }^{\mathrm{c}}$, Emmanuel Serrano ${ }^{\mathrm{d}}$, \\ José-Enrique Granados ${ }^{\text {e }}$, Francisco J. González ${ }^{\mathrm{f}}$, Paulino Fandos ${ }^{\mathrm{g}}$, Ramón C. Soriguer ${ }^{\mathrm{h}}$, \\ Georges Gonzalez ${ }^{\mathrm{b}}$, Jean Joachim ${ }^{\mathrm{b}}$, Jesús M. Pérez ${ }^{\mathrm{a}}$ \\ ${ }^{a}$ Departamento de Biología Animal, Biología Vegetal y Ecología, Facultad de Ciencias Experimentales, Universidad de Jaén. Campus las Lagunillas, s.n., E-23071 Jaén, Spain \\ ${ }^{\mathrm{b}}$ Laboratoire Comportement et Ecologie de la Faune Sauvage, Institut National de la Recherche Agronomique, BP 52627, F-31326 Castanet-Tolosan Cedex, France \\ ${ }^{c}$ Dipartimento di Produzioni Animali, Epidemiologia ed Ecologia, Università degli Studi di Torino, V. Leonardo da Vinci 44, IT-10095 Grugliasco (TO), Italy \\ dServei d’Ecopatologia de Fauna Salvatge, Facultat de Veterinària, Universitat Autònoma de Barcelona, Bellaterra, Spain \\ e Espacio Natural Sierra Nevada, Carretera Antigua de Sierra Nevada, km. 7. E-18071 Pinos Genil, Granada, Spain \\ ${ }^{\mathrm{i}}$ Laboratorio PROLAB. Carrera, 51. E-23600 Martos, Jaén, Spain \\ ${ }^{g}$ EGMASA, Avenida Johan G. Gutenberg, s.n., Isla de la Cartuja, E-41092 Sevilla, Spain \\ ${ }^{\mathrm{h}}$ Estación Biológica de Doñana (C.S.I.C). Avenida Americo Vespucio, s.n., Isla de la Cartuja, E-41092 Sevilla, Spain
}

\section{Keywords:}

Capra pyrenaica

Immunity

Inter-individual variability

Sarcoptes scabiei

Ungulate

\section{a b s t r a c t}

Host acquired immunity is a critical factor that conditions the survival of parasites. Nevertheless, there is a shortage of data concerning inter-individual immunological inequalities in wild mammals. Sarcoptic mange is a widespread parasitosis that severely affects mammals such as the Iberian ibex (Capra pyrenaica). Despite some work on the subject, the immune response to sarcoptic mange infestation is still a complex and poorly understood phenomenon. To improve knowledge of the host-Sarcoptes immunological interaction, 18 Iberian ibexes were experimentally infested. IgG levels were assessed using ELISA to test for potential factors determining the specific immune response to infestation. Previous exposure and sex appeared to affect the IgG response to infestation and our results suggest a sex-biased immunomodulation. We discuss the immunological pattern of host-Sarcoptes interactions and also suggest further lines of work that may improve the understanding of immunological interactions of host-Sarcoptes systems.

\section{Introduction}

Host acquired immunity (immune memory) is a critical factor that conditions the survival of parasites (Hudson and Dobson, 1995; Wilson et al., 2002). Available data on inter-individual inequalities in host-parasite interactions is uneven and differ according to the host and parasite taxa in question. Studies have tended to focus more on birds and endoparasites than on any other class of animals (Dobson, 1988; Clayton and Moore, 1997) and data for wild mammals, for instance, are scarce and more ambiguous. Some physiological inequalities have been described in small mammals (Khokhlova et al., 2004; Kristan, 2004), although for medium and large species most data are the product of analogies with human and domestic animals (Lloyd, 1995). Despite the many experimental studies that have described uneven

\footnotetext{
* Corresponding author. Address: Departamento de Biología Animal, Biología Vegetal y Ecología, Facultad de Ciencias Experimentales, Universidad de Jaén. Campus las Lagunillas, s.n., E-23071 Jaén, Spain. Fax: +34 953211873. E-mail address: mathieusar@hotmail.com (M. Sarasa).
}

clinical and physiological responses, inter-individual variability is often just acknowledged (e.g. Mörner and Christensson, 1984; Skerratt, 2003a,b) without being fully characterized.

Here we present details of an experiment on the immunological interaction between the aetiological agent of sarcoptic mange (Sarcoptes scabiei, Linnaeus 1758) and one of its wild hosts, the Iberian ibex (Capra pyrenaica, Schinz 1838). This sexually dimorphic mountain ungulate is endemic to the Iberian Peninsula (Pérez et al., 2002) and is affected by sarcoptic mange (Pérez et al., 1997) caused by a submacroscopic mite that burrows into the skin of domestic and wild mammals (Pence and Ueckermann, 2002; González-Candela et al., 2004). Sarcoptic mange affects animals at a broad spectrum of levels ranging from the individual phenotype (Serrano et al., 2007) to the population dynamics of the host species (Pence and Ueckermann, 2002). By the end of the twentieth century several Iberian ibex populations had experienced massive mortality rates (in some cases over $90 \%$ ) as a result of increasing epizootic episodes of sarcoptic mange (Fandos, 1991). Conservation managers and researchers have collaborated (for example, in this experiment) to explore strategies aimed at controlling this 
disease in natura and to prevent the extinction of this endemic ungulate, whose populations are only just recovering after centuries of multifactor population decline (Pérez et al., 2002).

Correlative studies of host-Sarcoptes interaction provide multiple trended data on epidemiology; nevertheless, these works often report an uneven distribution of sarcoptic mange in host populations (Pérez et al., 1997; Pence and Ueckermann, 2002). As well, experiments have detected inequalities and have sometimes revealed previous exposure to be one of the determining factors (Arlian et al., 1994; Skerratt, 2003a). However, a full characterization of inter-individual inequalities has not yet been carried out. In particular, few immunological studies have been conducted and, despite some available information suggesting the importance of humoral and cellular responses (Arlian, 1996), the immune response to sarcoptic mange remains complex and poorly understood (Pence and Ueckermann, 2002).

We employed an experimental approach with different hostparasite interaction sub-classes to test the following hypotheses:

1. According to previous studies on host-Sarcoptes immunological interaction (Falk, 1980; Arlian et al., 1994; Bornstein et al., 1995), infested as opposed to control animals are expected to develop a specific immunological response.

2. As immunity and parasitism are reported to vary with sex (Folstad and Karter, 1992; Hughes and Randolph, 2001), we expect there to be a lower specific response in males than in females.

3. As immunity is reported to vary with age (Lloyd, 1995), we expect there to be a lower specific response in juvenile animals than in adults.

4. According to the acquired immunity principle, secondary responses should reach higher levels (Wikel, 1996; Wakelin and Apanius, 1997) and so we expect there to be greater specific response in previously exposed animals than in naïve ones.

\section{Materials and methods}

\subsection{General experimental procedure}

The experimental buildings were located in southern Spain (Centro Las Mimbres, Parque Natural de las Sierras de Huétor, Granada). Eighteen Iberian ibexes Capra pyrenaica hispanica (Table 1) obtained from a stock reservoir protected from exposure to sarcoptic mange (Sierra Nevada National Space, $36^{\circ} 55^{\circ}-37^{\circ} 10^{\circ} \mathrm{N}, 2^{\circ} 56^{\circ}-$ $3^{\circ} 38^{\circ} \mathrm{W}$ ) were kept in small groups in separate enclosures. Special

Table 1

Ibexes and experimental sub-classes.

\begin{tabular}{lllll}
\hline Ind. & Sex & Age & $\begin{array}{l}\text { Groups in the first } \\
\text { trial }\end{array}$ & $\begin{array}{l}\text { Groups in the second } \\
\text { trial }\end{array}$ \\
\hline F1 & Female & 5 years & Infested & Reinfested \\
F2 & Female & 6 years & & \\
F3 & Female & 6 years & & \\
M1 & Male & 1 years & \\
M2 & Male & 1 years & \\
M3 & Male & 3 years & \\
M4 & Male & 3 years & \\
M5 & Male & 5 years & \\
M6 & Male & 7 years & \\
M7 & Male & 7 years & \\
M8 & Male & 1 years & \\
M9 & Male & 3 years & & \\
M10 & Male & 6 years & & \\
M11 & Male & 2 years & Control & \\
M12 & Male & 1 years & & \\
M13 & Male & 4 years & & \\
M14 & Male & 7 years & & \\
M15 & Male & 8 years & & \\
\hline
\end{tabular}

Ind. = individual reference. care was taken to avoid any transmission of the mites and special protective clothing and footwear were worn when visiting and handling the animals. In each enclosure, animals were able to move freely and had ad libitum access to food and water. Animals were kept under observation during an acclimatisation period of 6 weeks prior to the tests being carried out.

During the first experimental period ( 9 weeks, see Table 2), 13 ibexes were infested with low inoculums (load 6300 mites), while a group of 5 ibexes were maintained as a control group. At 74 days post infestation (dpi), animals were treated using doramectin (Dectomax $^{\circledR}, 10 \mathrm{mg} / 50 \mathrm{~kg} \mathrm{b.w.)}$ and then again at 89 dpi. A recovery period of 5 weeks was allowed after the second treatment with doramectin. The second experimental period began at $132 \mathrm{dpi}$ and all animals (both those from the control group and from the previously-infested group) were infested with low inoculums (load 6300 mites). On health grounds, animals were subsequently treated with doramectin at 208 and 223 dpi, as during the first experimental period.

\subsection{Manipulation of parasite loads and sampling}

The ibexes used in the experiment were infested with S. scabiei extracted from the skins of three naturally parasitized wild ibexes selected from the neighbouring Sierra Nevada massif. Mites were extracted from pieces of mangy skin by means of a thermal gradient induced by a light shone from below Petri dishes with black bottoms and transparent central areas (Andrews, 1981).

Mites were counted with a stereomicroscope and placed on a sterilized metallic support. Next, this support was fixed onto the ibex's previously shaved inter-scapular region using adhesive bands, thereby inducing contact between the mites and host's skin.

Blood samples were collected by venipuncture from the day of the first infestation until the end of the experiment (Table 2). Sampling followed the same calendar for all individuals (Table 2) as a means of creating a standardized data base. After clotting, blood samples were centrifuged at $200 \mathrm{~g}$ for $15 \mathrm{~min}$ and sera were stored at $-20^{\circ} \mathrm{C}$ in $1 \mathrm{ml}$ aliquots until required.

Skin scrapings were also performed to verify the success of mite establishment (Table 2).

\subsection{Immunological response estimates}

IgG antibodies are an essential weapon in acquired immunity since they identify and neutralize foreign antigens (Wikel, 1996). IgG levels were estimated using a serological test - a labelled avidin-biotin immunosorbent assay (LAB-ELISA) - that was developed to detect the specific humoral response to $\mathrm{S}$. scabiei in the Caprinae subfamily (Rambozzi et al., 2004). Antigen was obtained from living S. scabiei mites at different stages of development (Rambozzi et al., 2004). The optical density of processed samples was read at $405 \mathrm{~nm}$ with a spectrophotometer (Anthos 2010, Anthos Labtec Instruments, Wals, Austria). Potential cross-reactions were tested for, although there was no evidence of any cross-reaction with other potential causes of skin damage in ungulates (see Rambozzi et al., 2004).

Our analysis was focused on the quantitative responses to infestations, and not on the qualitative classification of healthy/mangy individuals. Consequently, we analysed the optical density of processed samples as a continuum and an indicator of increases in the IgG, but did not use any cut-off point.

\subsection{Statistical analyses}

The experimental design was uneven in its sex ratio and treatment of the animals tested (Table 1). Consequently, we performed a number of different analyses to test each of our predictions with 
each sub-set of experimental individuals. More specifically, we first examined the occurrence of a specific immune response in just males. Then, we analysed the factors determining the immune response to the first infestation in infested individuals. Next, during the second trial we examined the effect of reinfestation on immune response in males and analysed the factors determining the immune response to reinfestation in only reinfested individuals. Finally, to contrast with the results of the analysis cited above, we examined the factors determining the immune response in reinfested females and naïve males. Since data consisted of a longitudinal series of measurements from the same host animals, we used generalized additive mixed model analyses (GAMM; Verbeke and Molenberghs, 2000; Paterson and Lello, 2003; Wood, 2006; Zuur et al., 2007). Taking into account the characteristics of our data set and in order to apply the most informative method, we used an information-theoretic approach (Whittingham et al., 2006) based on the Akaike Information Criterion corrected for small sample sizes (AICc; Burnham and Anderson, 2002). Variables examined were "Group" (infested in the first trial or not), "Sex" (male or female) and "Age". Model selection identified in our analyses the most parsimonious model (lowest AICc; Burnham and Anderson, 2002) from the possible sub-sets, which ranged from the null model to a model with explanatory variables and their two-order interactions. The larger the Akaike difference (DAICc), the less plausible it is that the fitted model is the best model given the data set (Burnham and Anderson, 2002). Models with Akaike differences of less than 2 units and the relative importance of examined variables (RI) are commented upon (Burnham and Anderson, 2002), especially when the Akaike weight of the best model was moderate or low (Anderson et al., 2000, 2001). RI is measured by the sum of the Akaike weights for all models in which the variable appears (Burnham and Anderson, 2002) and expresses the probability that the considered exploratory factor is included in the "ideal" model explaining the variability in the dependent variable given the data set.

All analyses were performed using the R 2.6.2 statistical package (R Development Core Team, 2008).

\section{Results}

All infested ibexes developed characteristic mange lesions due to the experimental exposition to S. scabiei; the success of mite establishment was confirmed by skin scraping and microscopic examination.

\subsection{Analysis of the first infestation}

Infested males developed a specific serum antibody response during the first infestation period (Fig. 1). Taking into account only males (Table 3a), the model including "Time", "Group" and their interaction as explanatory factors was the

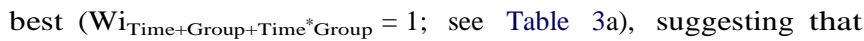
the observed response develops over time. The robustness of those results is highlighted by the multimodel inference. Of the explanatory variables, factors "Time", "Group" and their interaction had relative importances (RI) equal to one (see Table 3a).

The analysis specifically focusing on the infested individuals of both sexes confirmed that the specific response to infestation developed over time (Fig. 1), and that the sex of the host was a further key factor determining the response to the first trial (see Table 3b). The model including "Time", "Sex" and their

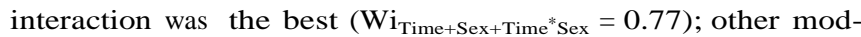
els had Akaike differences greater than 4 units (see Table 3b), 


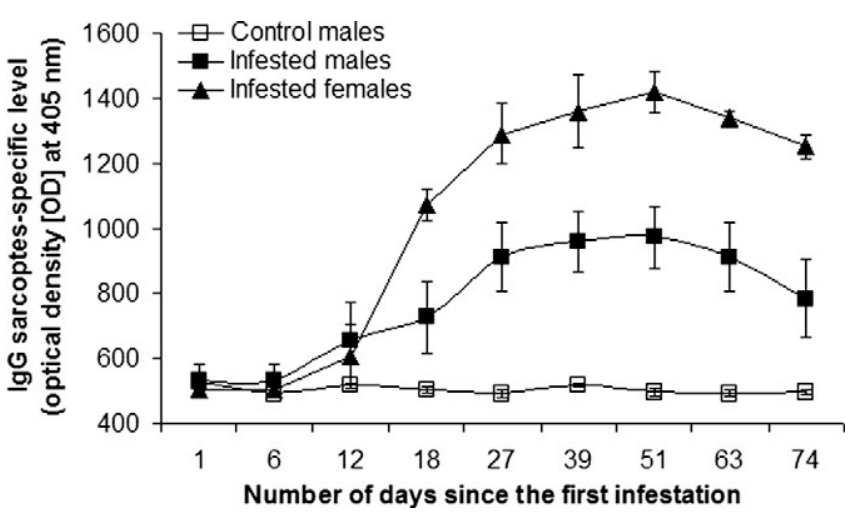

Fig. 1. Evolution of Sarcoptes-specific IgG antibody titers during the first infestation in control males, infested males and infested females. Points correspond to the mean optical density (OD) of processed samples within groups. The greater the OD, the higher the number of Sarcoptes-specific circulating IgG antibodies. Error bars represent standard error.

which underlines the poor support for these models given the data set. "Time", "Sex" and their interaction had very high relative importances in the observed pattern, while the age of infested animals only had a low RI (see Table 3b).

\subsection{Analysis of the second infestation}

Previously exposed males had lower responses over time than naïve ones (Fig. 2). Taking into account only males, in the second trial (Table 4a) the model including "Group" "Time" and their

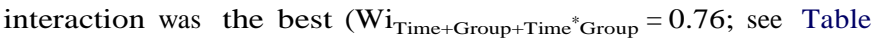
4a), suggesting that previous exposure to Sarcoptes has a negative effect on the development of the response over time. The multimodel inference reinforced these results since the RI of "Group" "Time" and their interaction was equal to one and the RI of "Age" and its interactions with other factors had lower values (Table 4a).

Among reinfested individuals, females had a higher specific response to reinfestation than males (Fig. 2). In the analyses which took into account reinfested animals of both sexes (see Table 4b), the model including "Time", "Sex" and their interaction was the

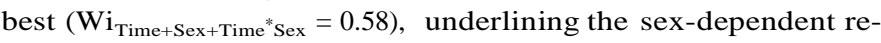
sponse to reinfestation. Likewise, of the explanatory variables

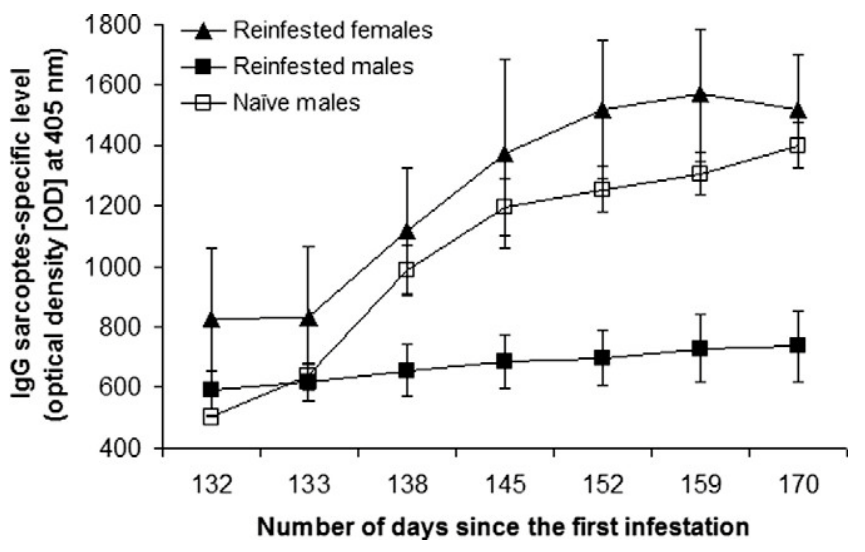

Fig. 2. Evolution of Sarcoptes-specific IgG antibody titers during the second infestation in na males, reinfested males and reinfested females. Points correspond to the mean optical density (OD) of processed samples within groups. The greater the OD, the higher the number of Sarcoptes-specific circulating IgG antibodies. Error bars represent standard error.

"Time", "Sex" and their interaction had a high RI and "Age" and its interactions with other factors appeared as having a low RI (Table 4b).

Finally, the response of naïve males to infestation seems not to diverge strongly from or to be slightly lower than the response of reinfested females (Fig. 2). In the analysis which took into account naïve males and reinfested females (see Table 4c), the model including "Time" was the best $\left(\mathrm{Wi}_{\text {Time }}=0.48\right)$, although two other models including "Sex" had Akaike differences of lower than 2 units, which suggests that these other two models could have also substantial support. Likewise, of the explanatory variables "Time" had a higher relative importance than both "Sex" and their interaction.

\section{Discussion}

4.1. Specific serum antibody responses to S. scabiei in the Iberian ibex

Iberian ibexes infested with sarcoptic mange produced a specific antibody response, which agrees with data from other hosts

Table 3

Model selection of the analysis of the first infestation.

\begin{tabular}{|c|c|c|c|c|c|c|c|c|}
\hline Model & $\mathrm{n}$ & $\mathrm{K}$ & AICc & DAICc & $\mathrm{L}(\mathrm{gi} / \mathrm{x})$ & Wi & R-sq(adj) & RI \\
\hline \multicolumn{9}{|c|}{ (a) Analysis of the response of "infested males" versus "control males" } \\
\hline Time + Group + Time*Group & 120 & 8 & -10.44 & 0.00 & 1.00 & 1.00 & 0.366 & Group: 1.00 \\
\hline Time + Group & 120 & 7 & 16.70 & 27.14 & 0.00 & 0.00 & 0.335 & Time: 1.00 \\
\hline Time & 120 & 6 & 22.64 & 33.07 & 0.00 & 0.00 & 0.125 & Group*Time: 1.00 \\
\hline Group & 120 & 5 & 64.30 & 74.73 & 0.00 & 0.00 & 0.173 & \\
\hline Null model & 120 & 4 & 71.10 & 81.54 & 0.00 & 0.00 & 0.000 & \\
\hline \multicolumn{9}{|c|}{ (b) Analysis of the response of infested individuals according to their sex and age } \\
\hline Time + Sex + Time*Sex & 104 & 8 & 4.04 & 0.00 & 1.00 & 0.77 & 0.461 & Time 1.00 \\
\hline Time + Sex + Age + Time*Sex + Time*Age & 104 & 11 & 8.48 & 4.44 & 0.11 & 0.08 & 0.465 & Sex 0.99 \\
\hline Time + Sex + Age + Time*Sex & 104 & 10 & 8.80 & 4.76 & 0.09 & 0.07 & 0.468 & Age 0.20 \\
\hline Time + Sex + Age + Time*Sex + Time*Age + Age*Sex & 104 & 12 & 11.03 & 6.99 & 0.03 & 0.02 & 0.460 & Time*Sex: 0.97 \\
\hline Time + Sex + Age + Time*Sex + Age*Sex & 104 & 11 & 11.29 & 7.25 & 0.03 & 0.02 & 0.464 & Time*Age: 0.11 \\
\hline Time + Sex & 104 & 7 & 11.73 & 7.69 & 0.02 & 0.02 & 0.453 & Age*Sex: 0.04 \\
\hline Time & 104 & 6 & 12.71 & 8.67 & 0.01 & 0.01 & 0.350 & \\
\hline Time + Age & 104 & 8 & 16.29 & 12.25 & 0.00 & 0.00 & 0.397 & \\
\hline Time + Sex + Age & 104 & 9 & 16.38 & 12.35 & 0.00 & 0.00 & 0.459 & \\
\hline Time + Age + Time*Age & 104 & 9 & 18.57 & 14.54 & 0.00 & 0.00 & 0.391 & \\
\hline
\end{tabular}

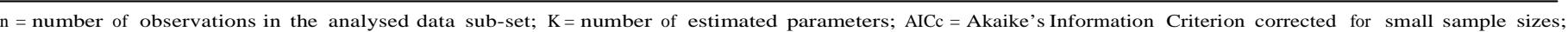

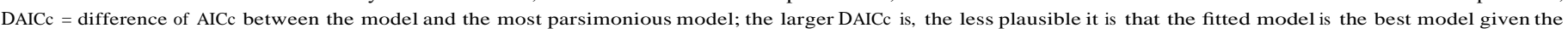

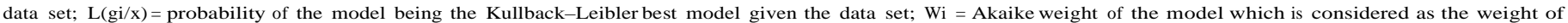

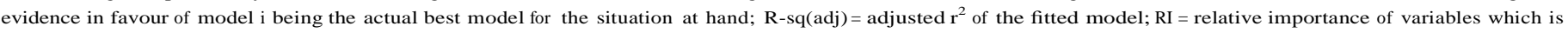

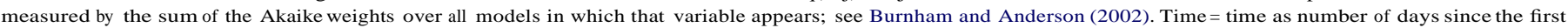
infestation; Group = infested or not in the first trial. Only the 10 first models are presented. 
Table 4

Model selection of the analysis of the second infestation.

\begin{tabular}{|c|c|c|c|c|c|c|c|c|}
\hline Model & $\mathrm{n}$ & $\mathrm{K}$ & AICc & DAICc & $\mathrm{L}(\mathrm{gi} / \mathrm{x})$ & Wi & R-sq(adj) & Rl \\
\hline \multicolumn{9}{|c|}{ (a) Analysis of the response of "naive males" versus "reinfested males" } \\
\hline Time + Group + Time*Group & 105 & 8 & -61.33 & 0.00 & 1.00 & 0.76 & 0.486 & Group 1.00 \\
\hline Time + Group + Age + Time*Group & 105 & 10 & -57.28 & 4.05 & 0.13 & 0.10 & 0.477 & Time 1.00 \\
\hline Time + Group + Age + Time*Group + Age*Group & 105 & 11 & -56.90 & 4.43 & 0.11 & 0.08 & 0.532 & Age 0.24 \\
\hline Time + Group + Age + Time*Group + Time*Age & 105 & 11 & -54.84 & 6.49 & 0.04 & 0.03 & 0.473 & Time*Group 1.00 \\
\hline Time + Group + Age + Time*Group + Time*Age + Age*Group & 105 & 12 & -54.41 & 6.92 & 0.03 & 0.02 & 0.527 & Group*Age 0.11 \\
\hline Time + Group & 105 & 7 & -47.96 & 13.37 & 0.00 & 0.00 & 0.413 & Time*Age 0.05 \\
\hline Time & 105 & 6 & -44.18 & 17.15 & 0.00 & 0.00 & 0.136 & \\
\hline Time + Group + Age + Age*Group & 105 & 10 & -43.76 & 17.57 & 0.00 & 0.00 & 0.471 & \\
\hline Time + Group + Age & 105 & 9 & -43.00 & 18.33 & 0.00 & 0.00 & 0.416 & \\
\hline Time + Group + Age + Time*Age + Age*Group & 105 & 11 & -41.13 & 20.20 & 0.00 & 0.00 & 0.466 & \\
\hline \multicolumn{9}{|c|}{ (b) Analysis of the response of reinfested individuals according to their sex and age } \\
\hline Time + Sex + Time*Sex & 91 & 8 & -102.57 & 0.00 & 1.00 & 0.58 & 0.454 & Time 1.00 \\
\hline Time + Sex & 91 & 7 & -100.22 & 2.35 & 0.31 & 0.18 & 0.441 & Sex 0.98 \\
\hline Time + Sex + Age + Time*Sex & 91 & 10 & -98.77 & 3.80 & 0.15 & 0.09 & 0.460 & Age 0.23 \\
\hline Time + Sex + Age + Time*Sex + Age*Sex & 91 & 11 & -97.75 & 4.83 & 0.09 & 0.05 & 0.633 & Time*Sex 0.76 \\
\hline Time + Sex + Age & 91 & 9 & -96.33 & 6.25 & 0.04 & 0.03 & 0.446 & Sex*Age 0.08 \\
\hline Time + Sex + Age + Time*Sex + Time*Age & 91 & 11 & -96.21 & 6.37 & 0.04 & 0.02 & 0.454 & Time*Age 0.04 \\
\hline Time + Sex + Age + Time*Sex + Time*Age + Age*Sex & 91 & 12 & -95.11 & 7.46 & 0.02 & 0.01 & 0.629 & \\
\hline Time + Sex + Age + Age*Sex & 91 & 10 & -94.75 & 7.82 & 0.02 & 0.01 & 0.621 & \\
\hline Time & 91 & 6 & -94.68 & 7.89 & 0.02 & 0.01 & 0.042 & \\
\hline Time + Age & 91 & 8 & -93.04 & 9.53 & 0.01 & 0.00 & 0.487 & \\
\hline \multicolumn{9}{|c|}{ (c) Analysis of the response of "naive males" versus "reinfested females" } \\
\hline Time & 56 & 6 & -44.17 & 0.00 & 1.00 & 0.48 & 0.571 & Time 1.00 \\
\hline Time + Sex + Time*Sex & 56 & 8 & -43.10 & 1.07 & 0.58 & 0.28 & 0.618 & Sex 0.52 \\
\hline Time + Sex & 56 & 7 & -42.74 & 1.43 & 0.49 & 0.24 & 0.620 & Time*Sex 0.28 \\
\hline Null model & 56 & 4 & -6.31 & 37.86 & 0.00 & 0.00 & 0.000 & \\
\hline Sex & 56 & 5 & -4.19 & 39.99 & 0.00 & 0.00 & 0.045 & \\
\hline
\end{tabular}

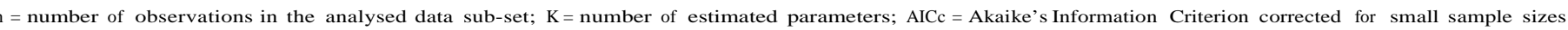

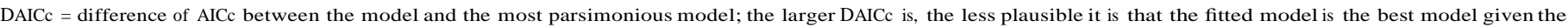

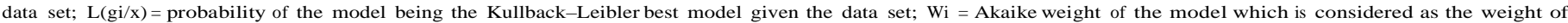

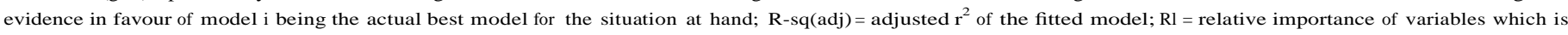

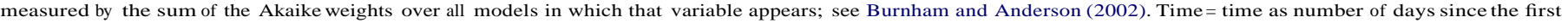
infestation; Group = infested or not in the first trial. Only the 10 first models are presented.

(Falk, 1980; Arlian et al., 1994; Bornstein et al., 1995) and with our first prediction. This finding diverges to some extent from Lastras et al. (2000), who observed no significant differences in IgG levels between healthy and infested Iberian ibexes from the same area, and we discuss this apparent contrast below. In line with the 3R principles (Russell and Burch, 1959), we limit the control group of our experiment to just male Iberian ibexes. However, on the basis of our results, the assumption of specific immune response to Sarcoptes in females as well is reasonable. Females are normally the immunologically stronger gender (Folstad and Karter, 1992); the chromosomal localization of the major histocompatibility complex has been reported in autosomes in several ungulate species (Ansari et al., 1988; Mäkinen et al., 1989) and there is no support to presuppose male-exclusive acquired immunity.

Uneven responses to Sarcoptes appeared during the first trial and further inequalities appeared after the reinfestation, which highlights the complexity of this topic. These inequalities confirm our second prediction, since sex appeared as a factor determining the immune response to infestation and reinfestation. Females had a higher acquired response to infestation and reinfestation than males, but the lack of marked difference between the response of reinfested females and naïve males indicates that a composite effect is taking place. Previously exposed males had lower IgG responses than naïve males, underlining the importance of experience. This paradoxical result contradicts our fourth prediction and the hypothesis of Shrank and Alexander (1967), who consider acquired immunity to Sarcoptes as a permanent feature. Arlian et al. (1994) obtained results with a similar trend in rabbits reinfested by Sarcoptes. Arlian et al. (1994) suggested that previous exposure induces immunoresistance and interpreted the subsequent reduction in humoral response as proof of resistance on the basis of the observed recovery from lesions. This, however, is not consistent with the acquired immunity principle, which implies that the first trial should have induced a greater response during the secondary exposure (Wikel, 1996; Wakelin and Apanius, 1997). The observed reduction in acquired immunity should be nearer to the effects of immunomodulation (Wikel et al., 1996). French et al. (1988) suggested that the experimental environment and probably self-grooming behaviour are key factors in recovery from mange lesions. The recoveries from lesions observed by Arlian et al. (1994) were probably favoured by factors other than the reduction of acquired immunity. Our results suggest that previous exposure to Sarcoptes may induce a sex-biased modulation of the IgG Sarcoptes-specific response in the Iberian ibex. Alternative hypotheses include a possible ineffective exposure to mites in previously infested males or an acquired immunity based on other antibodies isotopes such as IgE, possibly leading to the lack of IgG response in these individuals. However, the success of mite establishment was confirmed in all ibexes by the development of lesions and the skin scraping. Altered levels in other antibodies isotopes (particularly IgE) have been described by other authors as a response to Sarcoptes linked to atopic dermatitis, which would imply the development of an allergic response to Sarcoptes rather than an specific response able to eliminate the parasite (Falk, 1980). Consequently, the hypothesis of an ineffective exposure to mites or of acquired immunity based on other antibodies isotopes such as IgE, as confounding factors, have little support. In natura, females are also infested and die from sarcoptic mange; compared to males, the modulation of immunity in females might be delayed and this uneven immunological interaction will have to be examined in more detail in the 
future. This complex interaction may have led to difficulties in interpreting the results of correlative studies (Lastras et al., 2000), since the pathogenic experience of culled free-ranging animals is generally unknown.

\subsection{Sample size}

In our experiment, infestations were analysed in 18 Iberian ibexes, a larger sample size than those used in previous experiments on the effects of Sarcoptes on wild mammals (Samuel, 1981; Mörner and Christensson, 1984; Bornstein et al., 1995; Little et al., 1998; Skerratt, 2003a,b). Nonetheless, our experimental design was still a compromise between a manageable and ethically acceptable sample size and the number of variables to be examined. Nevertheless, the analysis of a longitudinal data set allowed us to identify several effects of the considered variables. The selected models generally had good support, as suggested by their Akaike weight, and our results are a substantial contribution to more precise knowledge of the complex pattern of inequalities that exist in the immunological interaction with Sarcoptes. Experience and sex appeared as key determining factors in the immune response to Sarcoptes; age did not seem to be very relevant, although we cannot exclude the possibility that additional subtleties may appear in future experiments with larger sample sizes or increased numbers of reinfestations.

\subsection{From immune response to the need for an integrated approach}

The effects of Sarcoptes on several components of the immune system were recorded, suggesting that unequal changes in the defences of the immune response take place. Sarcoptic mange infestation modulates splenic gene expression (Arlian et al., 2007), skews the Th1/Th2 immune response (Lalli et al., 2004), increases IgE antibodies and eosinophils, and decreases levels of IgA antibodies (Falk, 1980). These patterns, which resemble somewhat an allergy or an atopic dermatitis (Soothill et al., 1976), suggest that Sarcoptes induces complex interactions with host defences and even a multifaceted immunomodulation, as occurs in cases of infestation by other arthropod parasites (Wikel et al., 1996). Our results constitute the first record of such alteration by Sarcoptes in a wild mammal species. More studies will be required if we are to fully understand the impact of single and successive infestations on the multidimensional immune response of hosts and their modulation-allergy balances.

The modulation of immune responses appears to affect individuals unevenly. The observed male bias is especially interesting given that the second trial occurred in September-October, a period that coincides with pre-rutting and a season of hormonal changes (e.g. an increase in testosterone levels) in Iberian ibex and other Caprinae species (Pelletier et al., 2003; Toledano-Díaz et al., 2007). The role of timing (Tinsley, 1990; Robb and Forbes, 2005) has not been studied sufficiently in host-Sarcoptes systems. Further studies are still needed to highlight the physiological causes of observed inequalities and to analyze the possible relationship with reproductive costs in both sexes (Williams, 1966), and must take into account the seasonal differences of life history and reproductive investments.

\section{Conclusion}

Like other parasites (Shaw et al., 1998), the mites causing sarcoptic mange often appear unevenly distributed in the host population (Pérez et al., 1997; Pence and Ueckermann, 2002) and our results provide us with a better understanding of several of the expected factors that explain observed distributions. Nevertheless, since epidemiology only provides a general view of the phenomena, supplementary data on factors such as the occurrence of repeated-infestation and sex-specific morbidity and mortality rates are still needed to understand and to model observed general patterns (Smith et al., 1995).

We should note, as well, that, despite being probably an essential part of observed distributions, immunological inequalities are not the only mechanisms involved. Parasitism will not occur evenly since individuals are genetically different and do not all behave in the same fashion (Barnard and Behnke, 1990; Wakelin and Apanius, 1997). The relative effects of these factors, which are related to host-compatibility (Combes, 2001) and to the hostencounter probability (Bundy and Blumenthal, 1990), still need to be fully explored. Like the pieces of a puzzle, data on all dimensions of these interactions are required if we are to try to fully understand the causes and consequences of parasitism and hostparasite systems.

\section{Acknowledgments}

We would like thank J. Navarro and M.C. Pérez for their help during the experiment. Constructive comments were provided by A.J.M. Hewison, N. Morellet (INRA-CEFS, France), S. Losdat (University of Berne, Switzerland) and M. González-Candela (University of Murcia, Spain), and R. Alpízar-Jara (University of Evora, Portugal) provided advice on statistical procedures. Thank you also to Michael Lockwood and Agnès Sarasa for the English revision and two anonymous reviewers for the helpful review comments.

MS is supported by a MENRT grant (France) and ES by the Juan de la Cierva programme (MICINN, Spain). The Consejería de Medio Ambiente (Junta de Andalucía) and the University of Jaén (Spain) gave support to this study. The Plan Andaluz de Investigación (Junta de Andalucía, RNM - 118) and the MIUR (Ministero Italiano dell’Università e della Ricerca Scientifica, Project Code: Cofin 2004 - 2004078701) also partly supported the research activities. The experiments comply with the current laws of the country in which the experiments were performed.

\section{References}

Anderson, D.R., Burnham, K.P., Thompson, W.L., 2000. Null hypothesis testing: problems, prevalence, and an alternative. Journal of Wildlife Management 64, 912-923.

Anderson, D.R., Link, W.A., Johnson, D.H., Burnham, K.P., 2001. Suggestions for presenting the results of data analyses. Journal of Wildlife Management 65, 373-378.

Andrews, J.R.H., 1981. The extraction of Sarcoptes scabiei from mammalian hosts. Journal of Parasitology 67, 753-754.

Ansari, H.A., Hediger, R., Fries, R., Stranziger, G., 1988. Chromosomal localization of the major histocompatibility complex of the horse (ELA) by in situ hybridization. Immunogenetics 28, 1211-1432.

Arlian, L.G., 1996. Immunology of scabies. In: Wikel, S.K. (Ed.), The Immunology of Host- Ectoparasitic Arthropod Relationships. CAB International, Wallingford, pp. 232-257.

Arlian, L.G., Morgan, M.S., Vyszenski-Moher, D.L., Stemmer, B.L., 1994. Sarcoptes scabiei: the circulating antibody response and induced immunity to scabies. Experimental Parasitology 78, 37-50.

Arlian, L.G., Fall, N., Morgan, M.S., 2007. In vivo evidence that Sarcoptes scabiei (Acari: Sarcoptidae) is the source of molecules that modulate splenic gene expression. Journal of Medical Entomology 44, 1054-1063.

Barnard, C.J., Behnke, J.M., 1990. Parasitism and Host Behaviour. Taylor and Francis, London.

Bornstein, S., Zakrisson, G., Thebo, P., 1995. Clinical picture and antibody response to experimental Sarcoptes scabiei var. vulpes infection in red foxes (Vulpes vulpes). Acta Veterinaria Scandinavica 36, 509-519.

Bundy, D.A.P., Blumenthal, U.J., 1990. Human behaviour and the epidemiology of helminth infections: the role of behaviour in exposure to infection. In: Barnard, C.J., Behnke, J.M. (Eds.), Parasitism and Host Behaviour. Taylor and Francis, London, pp. 264-289.

Burnham, K.P., Anderson, D.R., 2002. Model selection and multimodel inference. A Practical Information-Theoretic Approach. Springer, New York.

Clayton, D.H., Moore, J., 1997. Introduction. In: Clayton, D.H., Moore, J. (Eds.), HostParasite Evolution: General Principles and Avian Models. Oxford University Press, Oxford, pp. 1-6. 
Combes, C., 2001. Parasitism. The Ecology and Evolution of Intimate Interactions. University of Chicago Press, Chicago.

Dobson, A.P., 1988. The population biology of parasite-induced changes in host behavior. Quarterly Review of Biology 63, 139-165.

Falk, E.S., 1980. Serum immunoglobulin value in patients with scabies. British Journal of Dermatology 102, 57-61.

Fandos, P., 1991. La cabra montés (Capra pyrenaica) en el Parque Natural de las sierras de Cazorla Segura y las Villas. ICONA-CSIC, Madrid.

Folstad, I., Karter, A.J., 1992. Parasites, bright males and the immunocompetence handicap. American Naturalist 139, 603-622.

French, F.E., Callcott, A.-M.A., Guillot, F.S., 1988. Artificial infestation of cattle in southeastern USA with Psoroptes ovis. Journal of Agricultural Entomology 5, 6974

González-Candela, M., León-Vizcaíno, L., Cubero-Pablo, M.J., 2004. Population effects of sarcoptic mange in barbary sheep (Ammotragus lervia) from Sierra Espuña Regional Park, Spain. Journal of Wildlife Diseases 40, 456-465.

Hudson, P.J., Dobson, A., 1995. Macroparasites: observed patterns in naturally fluctuating animal populations. In: Grenfell, B.T., Dobson, A.P. (Eds.), Ecology of Infectious Diseases in Natural Populations. Cambridge University Press, Cambridge, pp. 144-176.

Hughes, V.L., Randolph, S.E., 2001. Testosterone depresses innate and acquired resistance to ticks in natural rodent hosts: a force for aggregated distribution of parasites. Journal of Parasitology 87, 49-54.

Khokhlova, I.S., Spinu, M., Krasnov, B.R., Degen, A.A., 2004. Immune response to fleas in a desert rodent: effects of parasite species, parasite burden, sex of host and host parasitological experience. Journal of Experimental Biology 207, 2725-2733.

Kristan, D.M., 2004. Intestinal nematodes infection affects host life history and offspring susceptibility to parasitism. Journal of Animal Ecology 73, 227-238.

Lalli, P.N., Morgan, M.S., Arlian, L.G., 2004. Skewed Th1/Th2 response to Sarcoptes scabiei. Journal of Parasitology 90, 711-714.

Lastras, M.E., Pastor, J., Marco, I., Ruiz, M., Viñas, L., Lavín, S., 2000. Effects of sarcoptic mange on serum proteins and immunoglobulin $G$ levels in chamois (Rupicapra pyrenaica) and Spanish ibex (Capra pyrenaica). Veterinary Parasitology 88, 313-319.

Little, S.E., Davidson, W.R., Rakich, P.M., Nixon, T.L., Bounous, D.I., Nettles, V.F., 1998. Responses of red foxes to first and second infection with Sarcoptes scabiei. Journal of Wildlife Diseases 34, 600-611.

Lloyd, S., 1995. Environmental influences on host immunity. In: Grenfell, B.T., Dobson, A.P. (Eds.), Ecology of Infectious Diseases in Natural Populations. Cambridge University Press, Cambridge, pp. 327-361.

Mäkinen, E.A.M.A., Chowdhary, B.P., Andersson, L., Gustavsson, I., 1989. Chromosomal localization of the ovine major histocompatibility complex (OLA) by in situ hybridization. Hereditas 111, 87-90.

Mörner, T., Christensson, D., 1984. Experimental infection of red foxes (Vulpes vulpes) with Sarcoptes scabiei var. vulpes. Veterinary Parasitology 15, 159-164.

Paterson, S., Lello, J., 2003. Mixed models: getting the best use of parasitological data. Trends in Parasitology 19, 370-375.

Pelletier, F., Bauman, J., Festa-Bianchet, M., 2003. Fecal testosterone in bighorn sheep (Ovis canadensis): behavioural and endocrine correlates. Canadian Journal of Zoology 81, 1678-1684.

Pence, D.B., Ueckermann, E., 2002. Sarcoptic mange in wildlife. Revue Scientifique et Technique de l'Office International des Epizooties 21, 385-398.

Pérez, J.M., Ruiz-Martinez, I., Granados, J.-E., Soriguer, R.C., Fandos, P., 1997. The dynamics of sarcoptic mange in the ibex population of Sierra Nevada in Spain: influence of climatic factors. Journal of Wildlife Research 2, 86-89.

Pérez, J.M., Granados, J.E., Soriguer, R.C., Fandos, P., Márquez, F.J., Crampe, J.P., 2002. Distribution, status, and conservation problems of the Spanish ibex, Capra pyrenaica (Mammalia: Artiodactyla). Mammal Review 32, 26-39.

R Development Core Team 2008. R: a language and environment for statistical computing. R Foundation for Statistical Computing, Vienna, Austria.

Rambozzi, L., Menzano, A., Lavín, S., Rossi, L., 2004. Biotin-avidin amplified ELISA for detection of antibodies to Sarcoptes scabiei in chamois (Rupicapra spp.). Veterinary Research 35, 701-708.
Robb, T., Forbes, M.R., 2005. Success of ectoparasites: How important is timing of host contact? Biology Letters 1, 118-120.

Russell, W.M.S., Burch, R.L., 1959. The Principles of Humane Experimental Technique. Methuen \& Co Ltd., London.

Samuel, W.M., 1981. Attempted experimental transfer of sarcoptic mange (Sarcoptes scabiei, Acarina: Sarcoptidae) among red fox, coyote, wolf and dog. Journal of Wildlife Diseases 17, 343-347.

Serrano, E., Granados, J.E., Pérez, J.M., 2007. Sarcoptic mange and metapodial development in growing male Iberian ibex (Capra pyrenaica). Veterinary Parasitology 144, 375-379.

Shaw, D.J., Grenfell, B.T., Dobson, A.P., 1998. Patterns of macroparasite aggregation in wildlife host populations. Parasitology 117, 597-610.

Shrank, A.B., Alexander, S.L., 1967. Scabies: another epidemic? British Medical Journal 1, 669-671.

Skerratt, L.F., 2003a. Clinical response of captive common wombats (Vombatus ursinus) infected with Sarcoptes scabiei var wombati. Journal of Wildlife Diseases 39, 179-192.

Skerratt, L.F., 2003b. Cellular response in the dermis of common wombats (Vombatus ursinus) infected with Sarcoptes scabiei var wombati. Journal of Wildlife Diseases 39, 193-202.

Smith, G., Basañez, M.-G., Dietz, K., Gemmell, M.A., Grenfell, B.T., Gulland, F.M.D., Hudson, P.J., Kennedy, C.R., Lloyd, S., Medley, G., Nåsell, I., Randolph, S.E., Roberts, M.G., Shaw, D.J., Woolhouse, M.E., 1995. Macroparasite group report: problems in modelling the dynamics of macroparasitic systems. In: Grenfell, B.T., Dobson, A.P. (Eds.), Ecology of Infectious Diseases in Natural Populations. Cambridge University Press, Cambridge, pp. 209-229.

Soothill, J.F., Stokes, C.R., Turner, M.W., Norman, A.P., Taylor, B., 1976. Predisposing factors and the development of reaginic allergy in infancy. Clinical \& Experimental Allergy 6, 305-319.

Tinsley, R.C., 1990. Host behaviour and opportunism in parasite life cycles. In: Barnard, C.J., Behnke, J.M. (Eds.), Parasitism and Host Behaviour. Taylor and Francis, London, pp. 158-192.

Toledano-Díaz, A., Santiago-Moreno, J., Gómez-Brunet, A., Pulido-Pastor, A., LópezSebastián, A., 2007. Horn growth related to testosterone secretion in two wild Mediterranean ruminant species: the Spanish ibex (Capra pyrenaica hispanica) and European mouflon (Ovis orientalis musimon). Animal Reproduction Science 102, 300-307.

Verbeke, G., Molenberghs, G., 2000. Linear Mixed Models for Longitudinal Data. Springer-Verlag, New York.

Wakelin, D., Apanius, V., 1997. Immune defence: genetic control. In: Clayton, D.H., Moore, J. (Eds.), Host-Parasite Evolution: General Principles and Avian Models. Oxford University Press, Oxford, pp. 30-58.

Whittingham, M.J., Stephens, P.A., Bradbury, R.B., Freckleton, R.P., 2006. Why do we still use stepwise modelling in ecology and behaviour? Journal of Animal Ecology 75, 1182-1189.

Wikel, S.K., 1996. Immunology of the skin. In: Wikel, S.K. (Ed.), The Immunology of Host-Ectoparasitic Arthropod Relationships. CAB International, Wallingford, pp. $1-29$.

Wikel, S.K., Ramachandra, R.N., Bergman, D.K., 1996. Arthropod modulation of host immune responses. In: Wikel, S.K. (Ed.), The Immunology of Host-Ectoparasitic Arthropod Relationships. CAB International, Wallingford, pp. 107-130.

Williams, G.C., 1966. Natural selection, the cost of reproduction, and a refinement of Lack's principle. American Naturalist 100, 687-690.

Wilson, K., Bjornstad, O.N., Dobson, A.P., Merler, S., Poglayen, G., Randolph, S.E. Read, A.F., Skorping, A., 2002. Heterogeneities in macroparasite infections: patterns and processes. In: Hudson, P.J., Rizzoli, A., Grenfell, B.T., Heesterbeek, H., Dobson, A. (Eds.), The Ecology of Wildlife Diseases. Oxford University Press, New York, pp. 6-44.

Wood, S.N., 2006. Generalized Additive Models, an Introduction with R. Chapman and Hall/CRC, Boca Raton.

Zuur, A.F., Ieno, E.N., Smith, G.M., 2007. Analysing Ecological Data. Springer, New York. 